\title{
SJIAOS Discussion Platform
}

Launch of the 10th discussion: 'Statistics on difficult to measure population groups: Challenges to leave no-one not-included'

The 10th discussion will focus on the importance to be in official statistics as inclusive as possible and especially to statistically cover the - often very vulnerable - population groups that are difficult to measure because of a lack of administrative or register data and/or difficulties in approaching or accessing these groups. Examples of these groups are stateless people, refugees and homeless people. It also includes other population groups, that for a variety of reasons, are not included in vital registrations or other central administrative systems. Such inclusion in official statistics is relevant from the perspective of the Sustainable Development Goals, directed on targets for specific population groups, but also in the wider context of (the ethics of) covering in official statistics all and especially vulnerable population groups. Measuring such groups requires creatively applying all possible data sources ranging from administrative records to snowball data collection, to self measurement as well as automatic and geo-tracing/observations methodologies to cover them in official statistics

This 10th discussion is triggered by the manuscript 'Improving official statistics on stateless people: challenges, solutions, and the road ahead', by Mary Strode (Independent Consultant to UNHCR) and Melanie Khanna (Former Chief of the Statelessness Section, UNHCR) in Volume 37 (2021).

The discussion statements will concentrate on the need for such statistical information, the challenges in collecting them as well as aspects on confidentiality and protection in data sharing and it will stress the importance of data to be comparable over contexts and time and to use the same definitions, concepts, questions and methodologies. The discussion will also invite comments on the experiences gained and result achieved in developing guidelines for measuring and developing statistics for difficult to measure groups.

Several other discussions are still also on line on the SJIAOS Discussion platform (www.officialstatis tics.com)
The ninth discussion on the SJIAOS discussion platform is based on seven statements on 'New Developments in Training in Official Statistics'

https://officialstatistics.com/news-blog/demand-andformat-training-official-statistics

In the Statistical Journal of the IAOS, Volume 37/3, on 'New Developments in Training in Official Statistics' the recent trends in training in official statistics are discussed in 22 manuscripts. The need and rationale for training in official statistics and the necessity to anticipate on the recent developments, the requirements needed for training in Data Science, a method for assessing the type and content of this demand for training, an overview of existing training in official statistics initiatives, general trends in learning and training, and a selection of examples of training in domains of official statistics or in regions.

The eight discussion on the discussion platform focuses on the UN Fundamental Principles for Official Statistics

https://officialstatistics.com/news-blog/un-fundamen tal-principles-official-statistics-suitable-and-currentself-regulatory

This discussion builds on one hand on the manuscript 'Assessing compliance with the United Nations Fundamental Principles of Official Statistics: A Maturity Model for Continuous Improvement' complementing the Fundamental Principles with the assessment of their compliance by countries and regions based on a Maturity Model for Continuous Improvement, ${ }^{1}$ illustrating the acceptance of this main framework for high quality statistics as a still suitable instrument. On the other hand during the last decennium there where many events, as for example illustrated by the manuscript by Andreas Georgiou in Volume 37/1, ${ }^{2}$ where the principles where consciously or unconsciously ignored.

\footnotetext{
${ }^{1}$ Milicich, R., T. Dickinson, G. Van Halderen, T. Labor, H. Neven Assessing compliance with the United Nations Fundamental Principles of Official Statistics: A Maturity Model for Continuous Improvement. In SJIAOS Vol37/2.

${ }^{2}$ Georgiou, A.: The manipulation of official statistics as corruption and ways of understanding it, In SJIAOS Vol37/1.
} 
The objective of the discussion is twofold: first to generate knowledge and experience with the implementation, application and effectiveness of the Fundamental Principles, second to inquire especially for major improvements, both to the Fundamental Principles themselves as well as to the compliance and the enforcement of compliance.

The seventh discussion on the discussion platform focuses on Misuse of Statistics, based on the section on Misuse of Statistics in Volume 37 (2021), Nr. 1: Misuse of Statistics; Time to speak out

https://officialstatistics.com/news-blog/misuse-statis tics-time-speak-out

The seventh discussion focuses on Misuse of Statistics. It aims to centre around comments and contributions around the need for trustworthy information to guide decision making and enable citizens to understand issues that affect their health and livelihoods. Misuse of statistics is a phenomenon as old a statistics it self. Regulatory systems like the Fundamental Principles for Official Statistics, statistical laws and rules for ethical behavior of statisticians aim to avoid and whenever needed correct forms of misuse of statistics. The data revolution, new data sets (Big Data) and open data all cause an even more complex society with an increasing number of stakeholders that is supposed to comply with these official statistics quality and behavioral requirements. In times of crisis like we are now in at a world-wide scale, 'invites' even more than in normal times those who have an interest in specific figures to massage, manipulate or even falsify information. The impact of misuse of statistics or false statistics is apparent. All this makes a discussion on Misuse of statistics even more current, and surely justifies the second part of the title: Time to speak out.

The sixth discussion on the discussion platform: Successes and challenges of regional cooperation and capacity building in Statistics: the example of the Asia-Pacific region

The sixth discussion on the discussion platform centers around the themes of innovation and transformation in official statistics production and dissemination. The four statements are based on experiences from AsiaPacific countries as reflected in the special section on the Asia-Pacific Statistics week in Volume 36 (2020) Nr. 4: https://content.iospress.com/articles/statisticaljournal-of-the-iaos/sji200771.

This discussion aims to highlight, beyond the results and successes, challenges, problems and pitfalls of national and international initiatives to improve the national statistical systems of low and middle income countries. Participants will be invited to reflect on the role and impact regional organizations like UN ESCAP, international statistical organizations (for example custodian agencies for the SDG's) and support from individual donor countries can have. The discussion will emphasize experiences and lessons with deploying methods and tools to support the development of national statistical systems at the policy, organizational and individual levels.

The fifth discussion on the discussion platform centers around statements taken from Volume 36 (2020), Nr. 3, The Future of economic statistics

https://content.iospress.com/articles/statistical-jour nal-of-the-iaos/sji209007

The discussion focuses on the four inter-related and mutually reinforcing building blocks of the emerging new statistical business model for economic statistics: outreach and user consultation; statistical framework; institutional and statistical operations, and data stewardship; and statistical infrastructure and data solutions.

Under the purview of the United Nations Statistical Commission, consultation activities and discussions with the representatives of the national and international statistical organizations and senior economists led to the acknowledgement that the future system of economic statistics needs to be more responsive and agile to better meet the collective needs of users. Greater responsiveness of the statistical system can be achieved by allowing the statistical and institutional operations and supporting infrastructure greater experimentation, and by increased collaboration and co-investment in the areas of data access, data sharing and exchange, new data solutions and technological resources. The COVID 19 pandemic and its global impact has provided the official statistical community an opportunity to meet this challenge for official statistics collectively in demonstrating its resilience, maintaining its relevance, and proving its responsiveness.

The four statements focus on the most important elements of a new statistical business model that is needed to achieve such a more responsive and agile system of economic statistics. Main question is if we official statisticians and our environment are sufficiently up for the challenges, and adequately focused and resourced to make this new statistical business model a reality.

The fourth discussion on the discussion platform, launched in June 2020, centers around statements 
taken from the article by Andreas Georgiou and is still open for contributions: 'Pre-release access to official statistics is not consistent with professional ethics'

Vol 36 (2020), Nr. 2: https://content.iospress.com/ar ticles/statistical-journal-of-the-iaos/sji200620

Pre-release practice to official statistics varies across and within countries, with pre-release practiced widely: pre-release access by government and pre-release access by the press. In defending their policies and practices countries argue for and against specific pre-release options. Relevant questions in this discussion will be for example if advertised pre-release access by policy makers preclude the possibility of pressure (or the perception thereof) on the independent production of statistics to serve political/policy interests? Is pre-release to government impartial when it gives at least a head start to the party in power relative to its opposition? Does pre-release access by the press adequately protect the level playing field for market participants, and does not lead to profiteering by some? Do the benefits of prerelease outweigh the costs associated with the risks? Is there a need for strengthening the existing movement away from pre-release access and a tightening of the guidelines in codes of practice for official statistics?'

You are invited to contribute to the discussions on: www.officialstatistics.com

\section{Closed discussions}

The first discussion, kicked of in September 2019 is closed for contributions. The closing article for this discussion is published in the December 2020 issue (Vol36, 2020, Nr. 4, pp. 1299-1306). See: https://content.iospre ss.com/articles/statistical-journal-of-the-iaos/sji200722

The second discussion kicked of in December 2019, 'Reflections on the future of official statistics in a digital and globalized society' is also closed for discussion. The closing article is in issue (Vol37, 2021, Nr. 2).

The third discussion kicked of in March 2020 on the Population and Housing Censuses is also closed. The closing article can also be found in issue (Vol37, 2021, Nr. 2).

Two special discussions in the context of the Covid19 crises:

'Crises, politics and statistics: Official statistics in the context of the Covid-19 crisis, focussed on the roles of Official Statistics in the context of the Covid-19 crisis. It stated the important role that official statistics will have to play in the phase of world-wide recovery from the pandemic and the rapid investments and actions that are needed to fulfill properly this role. It also emphasis the importance of investing in achieving the objectives of the SDG indicators, the need to develop new statistics and using modern data sources, and last but not least the establishment of a new role of official statistics in the public statistical infrastructure.

The discussion 'Official statistics methods need investments to be robust enough to maintain sufficient product quality in times of economic downturns' is based statements extracted from the article 'Robust official business statistics methodology during COVID19-related and other economic downturns' by Paul A. Smith and Boris Lorenc (respectively. University of Southampton; Bright Lynx Research; European Network for Better Establishment Statistics). This article is available as blog on: https://officialstatistics.com/newsblog/robust-official-business-statistics-methodologyduring-covid-19-related-and-other.

\section{Some background on the SJIAOS discussion platform}

In August 2019 the Statistical Journal of the International Association for Official Statistics (SJIAOS) launched the new on-line platform for discussion on topics of significant relevance for official statistics (www.officialstatistics.com) as part of the SJIAOS website. The discussion platform invites you to contribute to important discussions at a time of your own choosing.

The ISI World Statistics Conference, the IAOS conference and Journals like the Statistical Journal of the $I A O S$, are the traditional platforms where views on new developments and important issues in Official Statistics are exchanged. However, conferences occur only a few times per year, journal issues are released maybe four times per year and typically only reach specific interest groups. This new on-line discussion platform of the SJIAOS is an opportunity for anyone working or interested in official statistics, to contribute to topical discussions, at your own convenience.

Every three months there is a new discussion item. With each issue of the SJIAOS, a new discussion topic will be launched via a leading article. Statements from this article will then invite you to post your opinion and arguments. Each discussion will run for a year and be closed with a concluding commentary by the article author(s). When fully up and running (after four journal issues), there will be four different discussions topics open for your contribution at any one time.

The discussion platform can be found on a prominent place on the new SJIAOS website (www.officialstatisti cs.com). Contributions have to be in English, have to 
be clear and concise, specifically addressing one of the statements and should not exceed 25 lines. When considered useful, references to a longer text (article, paper) can be added as an attachment. Contributors are required to register on the discussion platform. Anonymous contributions are not appreciated.

The SJIAOS discussion platform editor (James Whitworth) moderates the discussions and the quality of the contributions (but of course not on the positions taken), takes decisions on the integrity of the arguments and is available for support when needed.

Pieter Everaers

Editor-in-Chief

October 2021

Statistical Journal of the IAOS

E-mail: pevssjiaos@gmail.com 